\title{
Walter Brown Receives 1984 Von Hippel Award
}

During the Fall Meeting, hundreds of materials scientists witnessed the presentation of the 1984 Arthur von Hippel Award to Walter L. Brown, head of the Radiation Physics Research Department at AT\&T Bell Laboratories. The ceremony, held Wednesday evening, November 28 , was preceded by recognition of Student Award recipients and concluded with an entertaining and enlightening lecture by Brown on "Satiable Curtiosity and Scientific Progress."

MRS President Woody White opened the event by introducing the past recipients of the Von Hippel Award who were attending the ceremony in honor

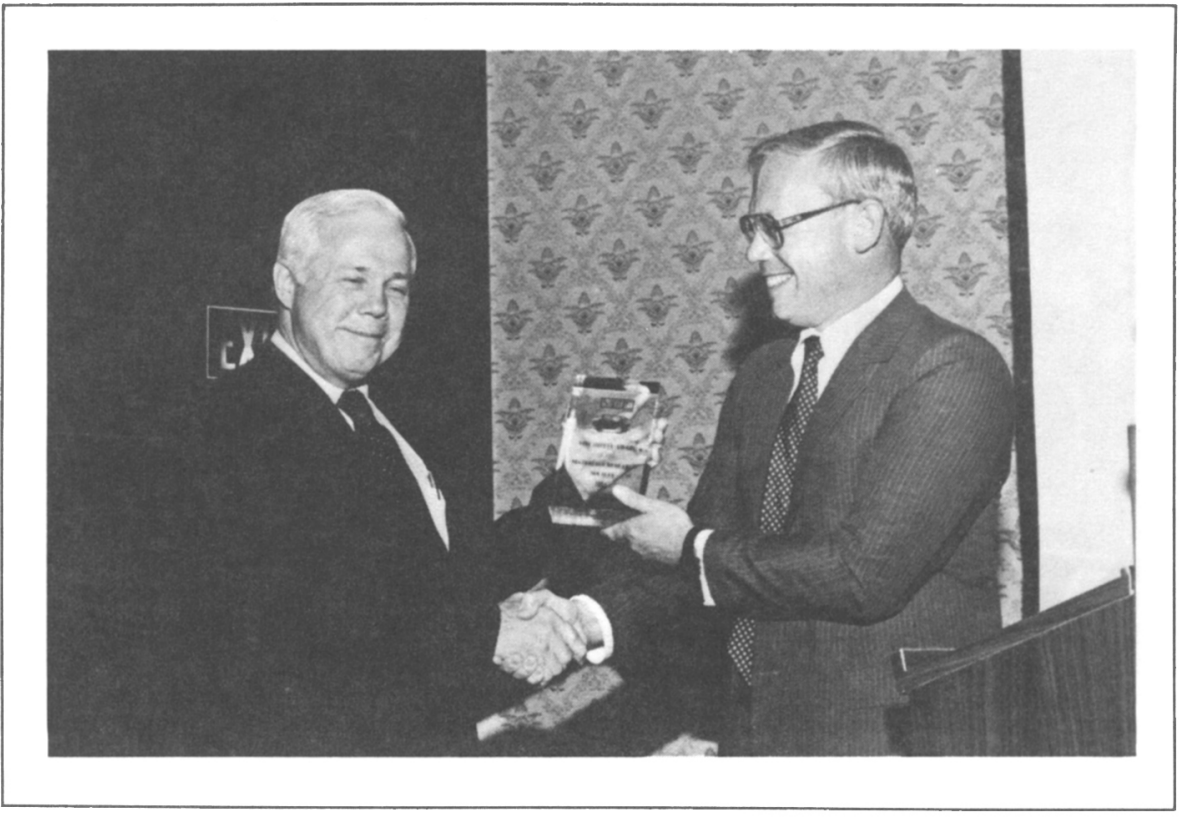

Walter Brown (left) accepts Von Hippel Award from Harry Leamy

my respect for his extensive record of achievement in the field of semiconductor science and technology and university-industry collaboration is immense. But I am further awed by his broad, indepth knowledge on any subject in materials science and his energy and dedication to his profession. His breadth of knowledge and unquenchable enthusiasm for research are renown. Wagers, in fact, have been known to be placed on whether or not he can be stumped on a given topic."

Attesting to Brown's dedication, Leamy went on to say that many times at Bell Labs, upon leaving work late in the evening, Leamy would encounter Walter Brown just entering his laboratory, fresh and smiling, as he prepared to start up work on a project or experiment at that unusual hour.

Although first appearing to be a particle physicist, Leamy stated, Walter Brown actually uses these tools for research of material. Leamy admitted that it took him a while at Bell Labs to comprehend Brown's nontraditional approach to materials research.

"Walter Brown has made a conscious career choice to be a research scientist," Leamy pointed out. "He is first, last, and always a dedicated scientist and stands as a model for all his colleagues and co-workers."

Presenting the award to Brown, he said, "It is an honor to know and work with a professional like Walter Brown, who is an inspiring example to all of us in the profession, and I am particularly honored to present to him on behalf of the Materials Research Society the 1984 Von Hippel Award."

Brown accepted the award and proceeded to deliver his lecture, using a Rudyard Kipling story to illustrate strengths that he viewed as important to any scientific research endeavor. He then provided an historical look at his career activities and scientific advancements made at Bell Labs since the early 1950 s.

\section{Dr. Brown's address, "'Satiable Curtiosity and Scientific \\ Progress," will appear in the next issue of the BULLETIN.}

\section{Von Hippel Award Presentation}

MRS Past President Harry Leamy, who presented the Von Hippel Award to Walter Brown, addressed the audience after comments by Arthur von Hippel. Giving his personal views of Walter Brown, Leamy said, "Having known and worked with Walter Brown for a number of years at Bell Labs, 


\section{Comments to Walter Brown \\ from Arthur von Hippel}

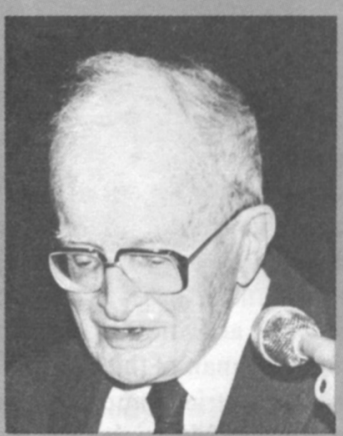

Arthur von Hippel
The Bell Telephone Laboratories have, for me, always been a symbol of excellence. When I first came to America as a Rockefeller Fellow in the early summer of 1927, I stopped in New York on my way to Berkeley to visit Davisson and Germer at Bell Telephone, at that time modestly housed downtown and engaged in their famous electron-diffraction experiment. A letter of recommendation from James Franck opened all doors, and I was deeply impressed by the excellent work and the warm reception. Dr. Fletcher was the director of the Laboratories. Fifteen years later, a son each of Davisson and of Fletcher were my PhD students at MIT.

I was on my way to Berkeley. The trip to California took eight days and nights by train and gave an overwhelming impression of the variety and beauty of this immense country. Our first major stop at Niagara Falls - not yet impoverished of water by power stations - provided an unforgettable spectacle and simultaneously a useful lesson.

One hour was allotted for the stop, and a taxi driver persuaded me that I could only see it all if he would drive me. We agreed upon a reasonable price; however, he drove me to a lonely spot and said I would now have to get out or pay much more.

Since I could not reach my train in time by walking back, I was at his mercy. The sum requested would have broken my account, so I told him that I would have to get the additional money from my baggage on the train. We saw the Falls and returned to the train. While he waited outside I boarded the train and swiftly locked myself into a lavatory. The whistle blew; the driver stomped through the train without finding me and had to jump off as the train pulled away from the station. I was on my way, somewhat wiser and with my small funds still intact.

It is a long way in space and time from those early American adventures to the present, but I am glad that old friendships are being renewed in honoring you, Dr. Brown, of the Bell Telephone Laboratories.

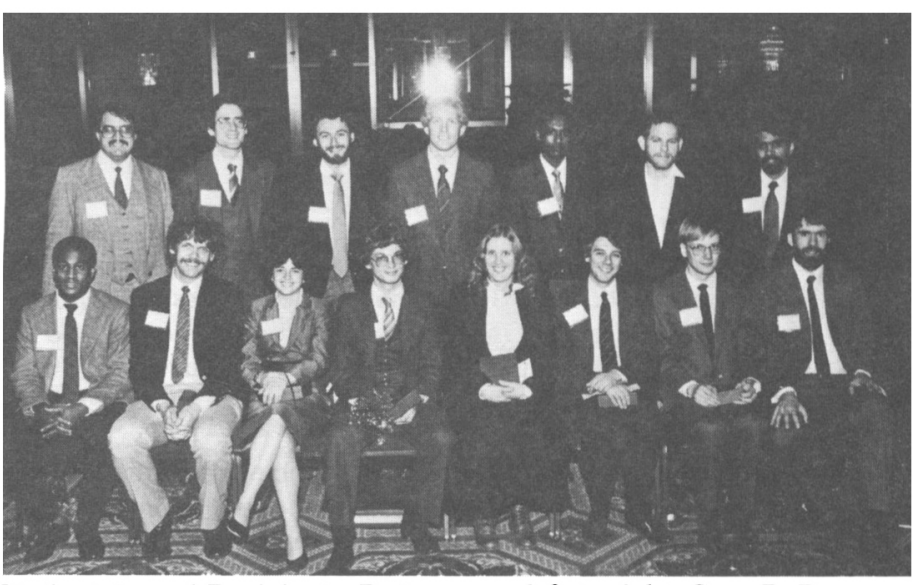

Student Award Recipients: Bottom row left to right: Gary B. Bronner, Slavik Kasztelan, James Kakalios, Bobbi Roop, Evert Jan van Loenen, Lourdes G. Salamanca-Riba, Kurt Sickafus, and Peter F. Green. Top row left to right: C. Tatar, Thomas C. Banwell, Ali S. M. Salih, Joseph K. Doychak, A. K. Kuruvilla, Theoren P. Smith, and Abderrafi M. Ougouag.

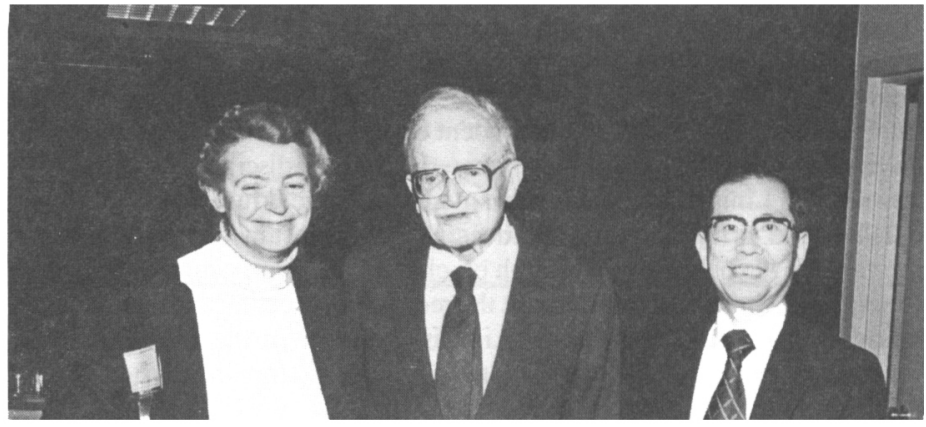

Mildred Dresselhaus, president, American Physical Society, Arthur von Hippel, and H. Kamimura, president of the Japanese Physical Society, attend the reception following the awards ceremony.

\section{The MRS Woody Award}

The inaugural presentation of a new MRS award, the "Woody," was recently made to and in honor of 1984 MRS President C. W. "Woody" White. The ceremony took place during the meeting of the MRS Council on Friday, November 30, immediately following the close of the Fall Meeting.

White accepted the unexpected award from Harry Leamy, chairperson of the MRS Awards Committee, who told the assembled Council that the award was instituted "to honor members of the Society whose organizational talents, energy, and unselfish service to the Society are typified by Woody White's performance as MRS President during 1984."

During the past year, White's leadership was tested more severely than was conceivable at the close of the 1983 Fall Meeting. The institution of a fledgling Headquarters required that White, with extensive help from Elton Kaufmann and the others on the Executive Committee, transmit the MRS culture and traditions to a new staff. Procedures for implementing the production and mailing of MRS literature were devised, a new computer system made functional, and a host of new activities were instituted under White's guidance.

The first MRS Equipment Exhibit and Job Placement Center and the transmittal of effective charters to each MRS Committee were all carried out by Woody White with grace, skill, and above all, energy.

Leamy emphasized that these activities are only examples of the multitude of accomplishments achieved on behalf of the Society through the driving

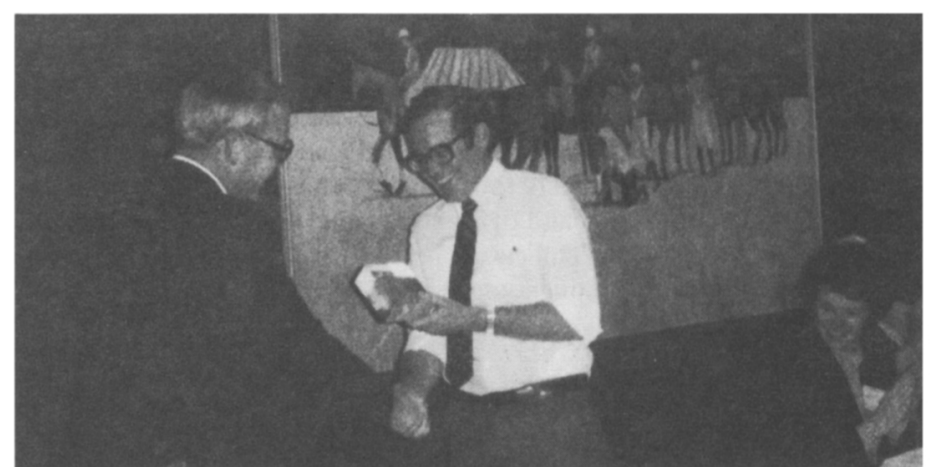

Harry Leamy (left) presents Woody White with the first Woody Award.

force of Woody White. Growth in the size and scope of the Society's activities occurred largely due to his efforts. It was for this reason the award was conceived.

In describing the award itself, Leamy said,"Other groups honor their esteemed members with awards such as the 'Oscar,' 'Emmy,' and 'Grammy.' We felt that Woody's outstanding example called for the creation of an award, and that his name lent itself beautifully to the purpose." 